\title{
Schöpfungsmythen und Kreativitätskonzepte im Alten Ägypten
}

\author{
VON JAN ASSMANN
}

\section{Vorbemerkungen}

Die Frage nach der Entstehung der Welt gehört zu den Urfragen der Menschheit. Es gibt gewiss keine Mythologie auf Erden, in der diese Frage nicht einen zentralen Rang einnähme. Schöpfungsmythen sind archaische Weltmodelle. Die heutige Wissenschaft produziert ebenfalls Weltmodelle, aber nicht mehr in der Form von Erzählungen, sondern von Begriffen und Formeln. Die heutigen Weltmodelle erheben den Anspruch, eine wesentlich größere Menge empirischer Daten zu integrieren als die mythischen Erzählungen, aber das bedeutet nicht, dass nicht auch die Mythen empirische Daten integrieren und den Status von Weltmodellen beanspruchen. In Schöpfungsmythen verständigte sich der frühe Mensch über den Aufbau der Wirklichkeit und seinen eigenen Platz in ihr. Schöpfungsmythen artikulieren daher das Welt- und Menschenbild früher Gesellschaften. Sie haben einen explanatorischen Bezug zur Wirklichkeit. ${ }^{1}$

In den Schöpfungsmythen der Völker spiegeln sich Konzepte menschlicher Kreativität. Hinter der Idee einer Schöpfung durch das Wort und der Sprachförmigkeit (oder „Lesbarkeit“) der Welt steht z.B. das Bewusstsein von der Schöpfermacht der Sprache. ${ }^{2}$ Jean François Lyotard hat diesen Zusammenhang zwischen Schöpfungsvorstellung und Kreativitätsbegriff noch am Beispiel der romantischen Genie-Ästhetik demonstriert: „Der Begriff der künstlerischen Schöpfung kommt aus der romantischen Ästhetik, aus der Ästhetik des Genies. Allerdings werden Sie mit mir übereinstimmen, dass die Vorstellung eines Schöpfers heute ein bisschen veraltet ist. ${ }^{{ }^{3}}$ Wenn in Ägypten die Tätigkeit des Schöpfers vor allem als eine Ausübung von Herrschaft gedacht wird, äußert sich darin das Menschenbild einer Gesellschaft, die den ersten Großstaat der Geschichte geschaffen hat. In „demiurgischen“

\footnotetext{
${ }^{1}$ Hönigswald, Vom erkenntnistheoretischen Gehalt alter Schöpfungserzählungen.

${ }^{2}$ A Assmann, Die Legitimität der Fiktion; H. Blumenberg, Die Lesbarkeit der Welt.

${ }^{3}$ Immaterialität und Postmoderne, 63.
} 


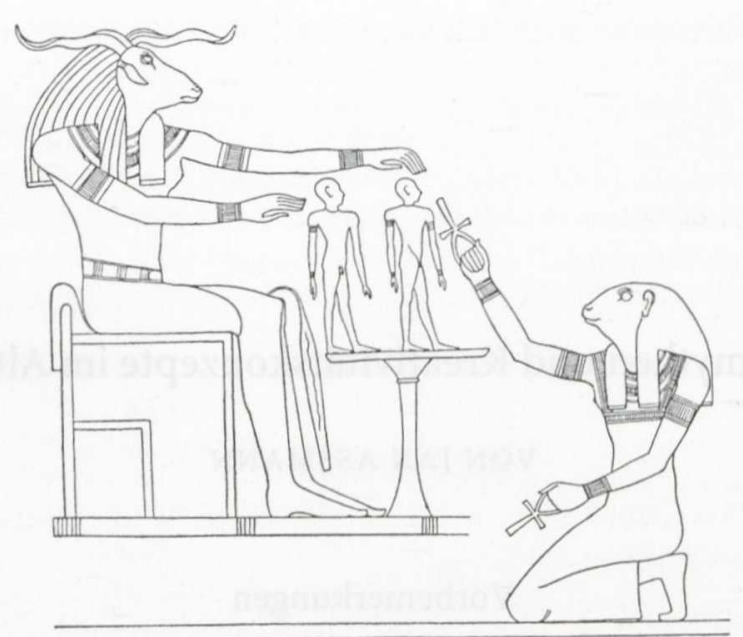

Abb. 1. Der widderschöpfige Chnum erschafft den Menschen auf der Töpferscheibe [1]

Schöpfergestalten, deren Schöpfertum sich in handwerklichen Formen manifestiert wie z.B. dem ägyptischen Schöpfergott Chnum, der die Lebewesen auf der Töpferscheibe formt, oder der Gott Ptah, der die Formen aus Gold gießt und aus Holz schnitzt, spiegelt sich das „Könnensbewusstsein“ (Christian Meier) und Kreativitätsgefühl des frühen Handwerks, das den Unterschied zwischen Kunst und Technik nicht kannte, was ebenso bedeutet, dass das Künstlerische noch völlig im Handwerklichen gebunden war, wie dass das Handwerkliche zum Künstlerischen hin offen stand und Meisterwerke hervorbrachte, die wie z.B. die ägyptischen Steingefäße der Frühzeit oder die Pyramiden des Alten Reichs mit heutigen Mitteln unerreichbar sind. In der Figur des Demiurgen in Platons Schöpfungsmythos drückt sich schon eine ganz andere Auffassung technischer Kreativität aus, die auf theoretischer, vor allem mathematischer Durchdringung der Formgesetze beruht und eine entsprechend mathematisierte und formalisierte Technologie ins Werk setzt, um die Welt zu schaffen. Schöpfungsbilder sind (auch) Menschenbilder. Andererseits sind sie jedoch auch Gegenbilder menschlicher Kreativität. Im Wirken von Schöpfergöttern manifestiert sich eine Tatkraft und Wirkungsmacht, der sich der Mensch unterworfen und unterlegen sieht und die er sich selbst vorenthalten weiß.

Der folgende Essay möchte sich den Schöpfungsmythen unter dem Gesichtspunkt der Kreativitätskonzepte widmen, die in ihnen greifbar werden. Dabei werden, dem beruflichen Schwerpunkt des Autors entsprechend, ägyptische Schöpfungsvorstellungen einen zentralen Raum nehmen und andere Schöpfungsmythen nur gelegentlich herangezogen werden. Allein die ägyptischen Schöpfungsmythen sind bereits von hinreichender Vielfalt, um 
ein großes Spektrum möglicher Kreativitätskonzepte greifbar werden zu lassen. Die Vergleiche mit anderen Kulturen beschränken sich zudem auf den Bereich der östlichen Mittelmeerwelt, also auf einen Kulturraum, der durch ein erhebliches Ausmaß an Interkonnektivität gekennzeichnet war. Die einzelnen Kulturen standen miteinander in vielfältigen Verbindungen, so dass innerhalb dieses Raumes auch verschiedenen Welt- und Menschenbilder miteinander in Berührung kamen und in fruchtbarem Austausch gerieten.

\section{Schöpfung und Kosmogonie}

Unsere Worte „Schöpfung“ und „Schöpfungsmythen“ legen die Auffassung nahe, dass sich die Menschen die Welt allgemein als das Resultat eines weltschaffenden Handelns vorstellten. Das ist jedoch keineswegs der Fall. Es gibt vielmehr sehr viele Mythen, denen zufolge die Welt von selbst entstand, ohne von einem oder mehreren Schöpfergöttern geschaffen worden zu sein. Daher muss man unterscheiden zwischen „Kosmogonien“ (Weltentstehungslehren ohne Schöpfergötter) und „Kosmopoiien“ (Welterschaffungslehren mit Schöpfergöttern). In den ägyptischen Schöpfungsmythen verbinden sich beide Elemente. Alle sind sich darin einig, dass der Ursprungsimpuls im Sinne der Entstehung und nicht der Schöpfung zu denken ist. Nach Ansicht der Lehre von Heliopolis, die nicht nur als die älteste, sondern auch als die zentrale und klassische ägyptische Schöpfungslehre zu gelten hat, in Bezug auf die alle anderen ägyptischen Schöpfungslehren Kommentare und Elaborationen darstellen, entstand die Welt mit dem „ersten Mal“ des Sonnenaufgangs, als der „von selbst entstandene“ Sonnengott aus dem Urwasser auftauchte und seine Strahlen in eine noch raumlose Welt hinausschickte.

Die Kosmogonie von Heliopolis stellt die Stadien der Weltentstehung als einen Stammbaum mit vier Generationen dar:

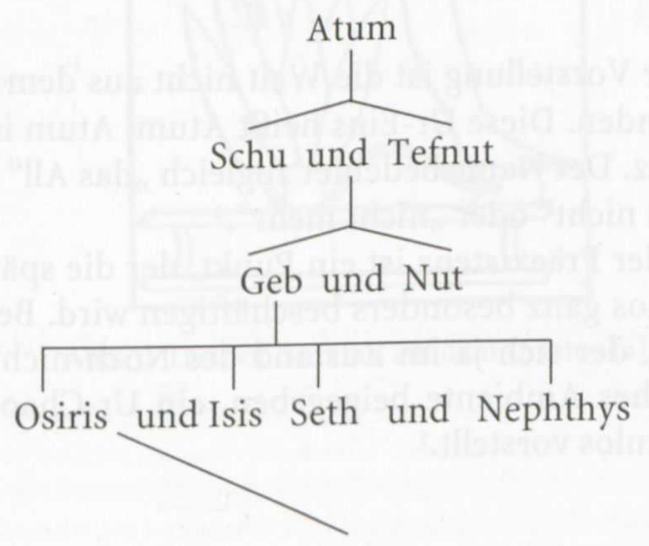

Horus 
Jeder Übergang von einer Generation zur anderen entspricht einem kosmogonischen Akt:

\section{Die Präexistenz}
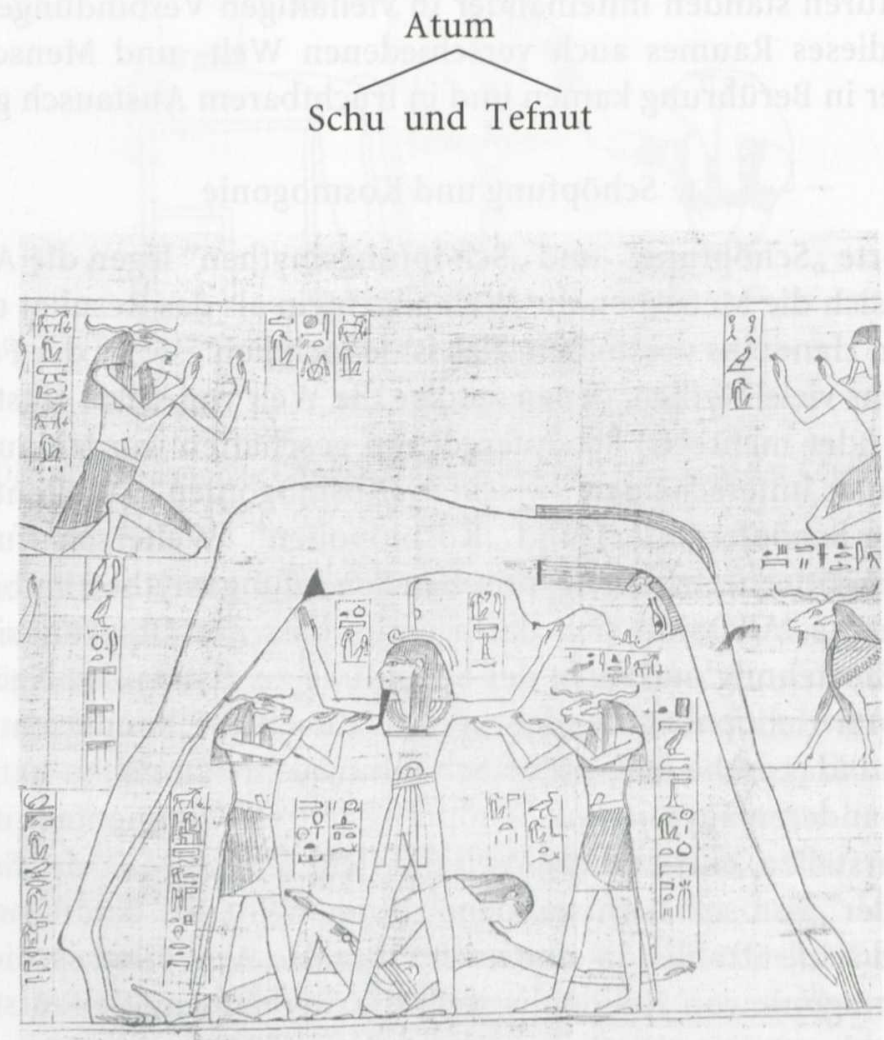

Abb. 2. Die Himmelsgöttin Nut über dem liegenden Geb gebeugt und von Schu gestützt [1]

Nach ägyptischer Vorstellung ist die Welt nicht aus dem Nichts, sondern aus der Eins entstanden. Diese Ur-Eins heißt Atum. Atum ist die Verkörperung der Präexistenz. Der Name bedeutet zugleich „das All“ und „das Nicht“ im Sinne von "noch nicht" oder "nicht mehr“. ${ }^{4}$

Das Mysterium der Präexistenz ist ein Punkt, der die späteren Ausgestaltungen dieses Mythos ganz besonders beschäftigen wird. Bei Atum bleibt es nicht. Diesem Gott, der sich ja im Zustand des Noch-nicht-seins befindet, wird ein vorweltliches Ambiente beigegeben, ein Ur-Chaos, das man sich lichtlos, endlos, formlos vorstellt. ${ }^{5}$

\footnotetext{
${ }^{4}$ Vgl. hierzu insbesondere Bickel, La cosmogonie égyptienne, 33-34.

${ }^{5}$ Bickel, 23-31.
} 
In dem „Schu-Buch“ der Sargtexte wird die Präexistenz ausgedeutet als das bewusstlose Dahintreiben des Urgottes Atum in der Urflut, dem Nun, dem als weitere Aspekte des Urchaos noch die Finsternis (Kuk), die Endlosigkeit (Huh) und die Weglosigkeit (Tenemu) zugesellt werden. Ihre klassische Ausgestaltung erhält diese Vorstellung vom Chaos in der Schöpfungslehre von Hermupolis. ${ }^{6}$ Hier wurde es in Gestalt einer frosch- und schlangenköpfigen Achtheit personifiziert, die vier Eigenschaften des Chaos in jeweils männlicher und weiblicher Ausprägung repräsentierten:

Kuk und Kauket: Finsternis

Huh und Hauhet: Endlosigkeit

Nun und Naunet: Wasser

Amun und Amaunet: Verborgenheit

Das Chaos ist nach ägyptischer Vorstellung kein Nichts, kein gähnender Abgrund (wie das griechische Wort "Chaos" es ausdrückt), sondern ein Urschlamm voller Keime möglichen Werdens. Aus diesem Urschlamm erhob sich nach der Schöpfungslehre von Hermupolis der Sonnengott, wiederum in spontaner Selbstentstehung, als Kind auf einer Lotosblüte.

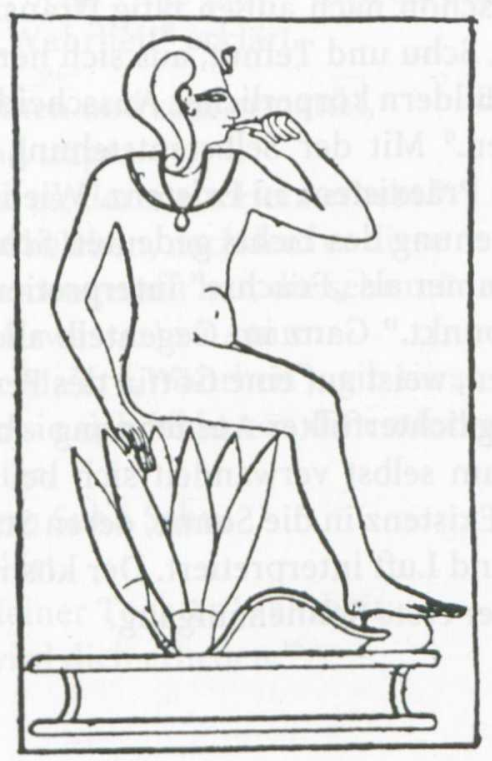

Abb. 3. Das Sonnenkind auf dem Urlotos [2]

\footnotetext{
${ }^{6}$ Sethe, Amun und die acht Urgötter.

7 Schlögl, Der Sonnengott auf der Blüte.
} 


\section{Der kosmogonische Augenblick: die Entstehung des Lichts}

Atum Cheprer, du bist aufgegangen auf dem Benben im Phönixhaus in Heliopolis.

Du hast ausgespien als Schu und ausgehustet als Tefnut.

Du hast deine Arme um sie gelegt als die Arme des Ka damit dein $\mathrm{Ka}$ in ihnen sei.

Atum, mögest du dir deine Arme auch um NN geben

(um dieses Bauwerk, um diese Pyramide) als Arme des Ka damit der Ka des NN in ihm sei, fest für immer und ewig. ${ }^{8}$

Der Übergang von der Präexistenz in die Existenz wird als Selbstentstehung des Urgottes gedeutet. Der Gott der präexistenten Einheit, Atum, verfestigt sich zur der Gestalt des Sonnengottes und taucht zum ersten Mal über dem Urwasser auf. Dieser erste Sonnenaufgang wird als ein Akt primordialer Selbstentstehung und zugleich als erste Schöpfungstat verstanden: als Erschaffung des Lichts. Indem der Gott entsteht (intransitive Kosmogonie), wird er zugleich auch schon nach außen tätig (transitive Kosmopoiie) und setzt zwei neue Wesen, Schu und Tefnut, aus sich heraus. Der Mythos greift hierfür zu den kruden Bildern körperlicher Ausscheidung: als Masturbation, Aushusten, Ausspucken. ${ }^{9}$ Mit der Selbstentstehung des Urgottes ereignet sich der Umschlag von Präexistenz in Existenz. Wie in der Bibel wird dieser Umschlag als die Entstehung des Lichts gedeutet. Schu ist der Gott der Luft. Tefnut wurde bisher immer als „Feuchte “ interpretiert. ${ }^{10}$ Dafür gibt es überhaupt keinen Anhaltspunkt. ${ }^{11}$ Ganz im Gegenteil: alles, was wir von Tefnut aus den Texten erfahren, weist auf eine Göttin des Feuers hin. Luft und Feuer - d.h. die Entstehung lichterfüllter Ausdehnung - bilden das erste kosmogonische Stadium. Atum selbst verwandelt sich bei seinem Übergang von der Präexistenz in die Existenz in die Sonne, deren Strahlung der Mythos als Gluthauch aus Feuer und Luft interpretiert. Der kosmogonische Augenblick ist nichts anderes als der erste Sonnenaufgang.

\footnotetext{
${ }^{8}$ Sethe, Pyramidentexte (im Folgenden abgekürzt als PT), Bd. II, $\$ \$ 1652 \mathrm{a}-\mathrm{c}-1653 \mathrm{a}-\mathrm{d}$.

${ }^{9}$ Bickel, $72-86$.

${ }^{10}$ S. hierzu Barta, Untersuchungen zum Götterkreis der Neunheit, 89-94, der in 89 Anm. 9 die ältere Literatur zu diesem Punkt aufführt. Ursula Verhoeven meldet zurecht in ihrem Artikel „Tefnut“, in: Lexikon der Ägyptologie VI, 1985, 296-304, vorsichtige Zweifel an der konventionellen Deutung der Tefnut als Göttin der Feuchtigkeit an, ohne allerdings eine alternative Deutung vorzutragen.

${ }^{11}$ Vgl. Bickel, 169.
} 
In den Sargtexten aus der Zeit um 2000 v. Chr. erfährt diese Vorstellung vom kosmogonischen Augenblick eine neue Deutung und Ausgestaltung. Der kosmogonische Augenblick wird hier als der Moment dargestellt, in dem Atum zu Bewusstsein kommt und aus handlungsunfähiger Mattigkeit in Bewusstsein, Wille und Handlung eintritt. Dieser Moment der Selbstentstehung wird als „Selbstverdreifachung“ gekennzeichnet: „Als er Einer war und zu Dreien wurde". ${ }^{12}$ Der spätere Text macht klar, dass man sich diesen Vorgang auf keinen Fall in der Form von Zeugung und Geburt vorstellen darf, indem er den Luftgott Schu sagen lässt: „Nicht hat er mich geboren mit seiner Faust, nicht hat er mich in Schwangerschaft getragen mit seiner Faust “ ${ }^{13}$ Man hat immer angenommen, diese Aussage würde sich gegen das krude Bild der Masturbation wenden ${ }^{14}$; aber daran hat der Ägypter keinen Anstoß genommen. Was hier zurückgewiesen wird, ist vielmehr die Vorstellung, Atum habe Schu und Tefnut geschaffen. Der kosmogonische Augenblick soll nicht als Schöpfung, sondern als Selbstentfaltung gedacht werden. Schu und Tefnut waren bei Atum vor aller Welt und bildeten mit ihm zusammen die Ureinheit, die zu Dreien wurde.

In diesem Text aus dem frühen 2. Jahrtausend wird der Mythos in einer Weise ausgedeutet, die bereits an die allegorisierende Mytheninterpretation eines Plutarch erinnert. Schu - die Luft - wird als "Leben“ und Tefnut - das Feuer oder Licht - als „Wahrheit" erklärt.

„Ich bin am Schwimmen und sehr ermattet, meine Glieder (?) sind träge.

Mein Sohn ,Leben' ist es, der mein Herz erhebt. ${ }^{15}$

Er wird meinen Geist beleben, nachdem er diese meine Glieder zusammengerafft hat, die sehr müde sind.

Da sprach Nun (das Urwasser) zu Atum:

,Küsse deine Tochter Ma'at (,Wahrheit'), gib sie an deine Nase!

Dein Herz lebt, wenn sie sich nicht von dir entfernen.

Ma'at ist deine Tochter, zusammen mit deinem Sohn Schu, dessen Name, Leben' ist.

Du wirst essen von deiner Tochter Wahrheit;

dein Sohn Schu, er wird dich erheben. ${ }^{16}$

${ }^{12}$ de Buck, Coffin Texts (im Folgenden abgekürzt als CT), Bd. II, 39e. Bickel, 37.

${ }^{13}$ CT I 354 c; Bickel, 79.

${ }^{14}$ Z.B. R.O. Faulkner, „Some notes on the god Shu“, in: JEOL (Jaarb. Ex Oriente Lux) VI/18, $1964,266$.

15 D.h. „mein Bewusstsein erweckt".

${ }^{16}$ CT II, 34g-35h [8o]; Bickel, $48 \mathrm{f}$. 
Da sagte Atum: ,Tefnut ist meine lebendige Tochter, sie ist zusammen mit ihrem Bruder Schu. ,Leben' ist sein Name, ,Wahrheit' ist ihr Name.

Ich lebe zusammen mit meinem Kinderpaar, zusammen mit meinem Zwillingspaar, indem ich mitten unter ihnen bin, der eine an meinem Rücken, die andere an meinem Bauch. ,Leben' schläft mit meiner Tochter, Wahrheit', eines in mir, eines um mich herum, ich habe mich aufgerichtet zwischen ihnen, indem ihre Arme um mich waren." ${ }^{17}$

Auf einer weiteren Stufe der Ausdeutung werden im selben Text SchuLeben und Tefnut-Wahrheit dann auch als Neheh („unendliche Zeit“) und Djet („unwandelbare Dauer") bezeichnet: „Denn Schu ist Neheh, Tefnut ist Djet "“18; „Ich bin Neheh, der Vater der Heh-Götter, meine Schwester Tefnut ist Djet". ${ }^{19}$ Neheh und Djet sind Begriffe für die Fülle und Unabsehbarkeit der Zeit. Dabei bezeichnet Neheh die unaufhörliche Bewegung der in sich kreisenden Zeit, Djet die unendliche und unwandelbare Dauer dessen, was sich in der Zeit ereignet und vollendet hat. Mit dem Licht entsteht also in dieser Ausdeutung zugleich auch die Zeit in ihren beiden Aspekten der zyklischen Wiederholung und der bleibenden Dauer.

\section{Die Entstehung des Raumes (Himmel und Erde) ${ }^{20}$}

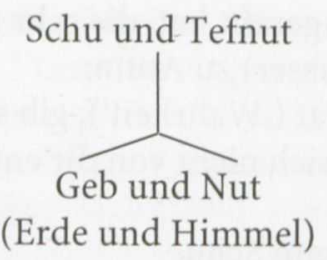

Die Kinder von Schu und Tefnut oder Luft und Feuer sind Geb und Nut, die Götter von Erde und Himmel. Auf die Entstehung des Lichts in der Form des ersten Sonnenaufgangs folgt die Entstehung des kosmischen Raumes, der im Licht sichtbar wird. Nach der Lehre von Heliopolis bewegen wir uns auch hier noch immer im Paradigma der Kosmogonie, des intransitiven Werdens. Im Laufe der ägyptischen Religionsgeschichte tritt aber der transitive Aspekt

17 CT II, 32b-33a [8o]; Bickel, 49-51.

${ }^{18}$ CT II, 28d [80]; Bickel, 134.

19 CT II, 22a; 23 a,c [78]; Bickel, 134 f.

${ }^{20}$ Bickel, 176-198. 
der Schöpfung immer stärker hervor. Da sind Himmel und Erde, genau wie in der Bibel, die alles entscheidende Schöpfungstat des selbstentstandenen Gottes. Der folgende Hymnus aus der 18. Dynastie preist den Selbstentstandenen als Schöpfer von Himmel und Erde:

Der sich verkörperte in Verkörperungen, der seinen Leib schuf, der seine Gestalt bildete, sich schuf mit seinen Armen, der hervorkam [in] spontaner [Selbstentstehung] alle seine Glieder redeten mit ihm Er hat sich selbst gebaut, bevor Himmel und Erde entstanden waren, als das Land im Urwasser war inmitten der «müden Flut».

Da hat er angefangen, dieses Land zu erschaffen, indem er festsetzte, was aus seinem Munde hervorging.

Du hast den Himmel hochgehoben und den Erdboden niedergestreckt, um das Land weitzumachen für dein Bild!

Du hast deine erste Gestalt angenommen als Sonnengott, um die beiden Länder zu erhellen für das, was du geschaffen hast als [Plan] deines Herzens, als du allein warst. ${ }^{21}$

Für die Frage nach Zusammenhängen zwischen Schöpfungsvorstellungen und Kreativitätskonzepten ist dieser kosmogonische Schritt, die Entstehung von Himmel und Erde und damit des Raumes von entscheidender Bedeutung, allerdings weniger in der Form der Entstehung oder Erschaffung, als vielmehr der Trennung von Himmel und Erde. Mit dieser Trennung entsteht erst der Raum, in dem menschliche Kreativität sich entfalten kann. Davon erzählt ein Mythos, der diese Trennung mit einer menschlichen Schuld in Verbindung bringt. Genau wie im biblischen Paradiesesmythos wird auch im ägyptischen Mythos durch ein menschliches Vergehen eine Trennung herbeigeführt, die überhaupt erst menschliche Kreativität freisetzt. Darauf werden wir im nächsten Kapitel eingehen. Hätten sich die Götter nicht an den Himmel zurückgezogen, wären die Menschen immer wie kleine Kinder geblieben, ebenso wie in der Bibel, wo sie durch das Essen der verbotenen Frucht zwar das Paradies verloren, aber das Wissen um gut und böse, d.h. die Entscheidungsfreiheit über die anzustrebenden Ziele und damit eine der Grundbedingungen menschlicher Kreativität gewannen.

\section{Die Entstehung des Todes und der Kultur}

Der entscheidende Schritt in den Staat, die Kultur und die Geschichte bedeutet dann die Zeugung der vierten Göttergeneration durch Geb und Nut:

${ }^{21}$ Hymnus von Tura, in: Verf., Ägyptische Hymnen und Gebete (im folgenden: ÄHG), Nr. 88, (um 1400 v. Chr.). 


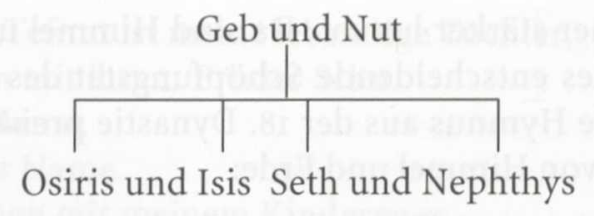

Dieses Stadium verbindet sich mit der Vorstellung einer Gründung der kulturellen Institutionen. Jetzt entstehen Zeit und Geschichte. Daher gehört zu dieser Generation auch Horus hinzu, der als Sohn von Isis und Osiris eigentlich die fünfte Generation bildet. Der Mythos spricht aber von fünf Kindern der Nut und erzählt, dass Isis und Osiris sich schon im Mutterleib begattet hätten, sodass Nut auch deren Kind Horus zur Welt brachte. Der Sinn dieser Überlieferung ist natürlich, dass in dieser Fünfheit eine zeitliche Dynamik angelegt ist, die sich in der endlosen Kette der Horusverkörperungen in Gestalt der Könige als Geschichte entfaltet.

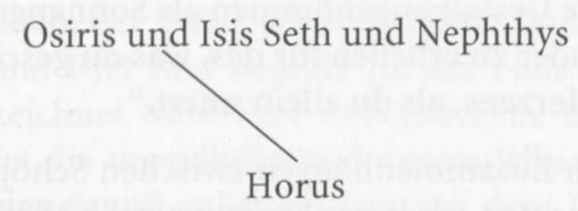

Diese „fünf Kinder der Nut" haben keine eindeutige kosmische Zuordnung mehr. Die Welt ist mit den ersten drei Generationen entstanden und beginnt sich mit der vierten in die Geschichte zu entfalten. Der Thron der Schöpfungsherrschaft geht von Geb auf Osiris über. Dieser hat nun als erster der göttlichen Herrscher einen Rivalen in Gestalt seines Bruders Seth. Dadurch entsteht der Konflikt, der die Geschichte ins Rollen bringt. Von diesem Konflikt handeln andeutungsweise Formeln, die in die Welt vor der Schöpfung zurückgreifen und dafür die einzelnen Stadien der Weltentstehung noch einmal rekapitulieren:

Der König ist geboren im Urwasser,

als der Himmel noch nicht entstanden war,

als die Erde noch nicht entstanden war,

als die beiden Randgebirge noch nicht entstanden waren,

als die Furcht noch nicht entstanden war, die entstand um das Horusauge. ${ }^{22}$

Das „Horusauge“ ist die Herrschaft, um die der Konflikt entbrennt. Von den Urgöttern heißt es, dass sie

${ }^{22}$ PT, \$1040a-d. 
geboren wurden, als der Zorn noch nicht entstanden war,

als der Lärm noch nicht entstanden war, als die Lästerung noch nicht entstanden war, als die Störung noch nicht entstanden war, als das Horusauge noch nicht ausgestoßen war, als die Hoden des Seth noch nicht abgeschnürt waren. ${ }^{23}$

Der folgende Text macht deutlich, worum es bei diesem Versuch geht, über die Stadien der Weltentstehung hinaus auf den Ursprung zurückzugreifen:

Die Mutter des Königs ist schwanger geworden mit ihm als einem

Nutbewohner

gebildet worden ist der König von seinem Vater Atum

als der Himmel noch nicht entstanden war, als die Erde noch nicht entstanden war

als die Menschen noch nicht entstanden und die Götter noch nicht

gebildet waren,

als der Tod noch nicht entstanden war

$\mathrm{N}$ entgeht dem Todes-Tage wie Seth seinem Todestag entging ${ }^{24}$

Auch der Tod ist einmal entstanden, und wer sich auf einen Ursprung vor der Entstehung des Todes zurückführen kann, der ist ihm enthoben. Der Tod kam in die Welt mit der vierten Göttergeneration. Seth hat seinen Bruder umgebracht, den Leichnam zerstückelt und die Glieder in ganz Ägypten verstreut. Isis hat die Teile gesucht, den Leichnam zusammengesetzt und zusammen mit ihrer Schwester Nephthys und vielen beistehenden Gottheiten, Horus, Anubis, Thot, Geb und Nut, Schu und Tefnut, die vier Söhne des Horus den Toten bestattet.

Die Pyramidentexte, aus denen die bisher betrachteten Zitate stammen, stammen aus den Totenritualen der Könige des Alten Reichs, und alle diese Götter haben nicht nur eine Rolle in der Weltentstehungslehre, sondern auch im Totenritual. Der Totenkult ist Mitte und Rahmen dieses ganzen Diskurses, und die Weltentstehung ist hier vor allem deshalb wichtig, um die kosmogonischen Energien zur Behandlung des Todes einzusetzen.

So wie die Empörung der Menschen gegen den Sonnengott die Trennung von Himmel und Erde herbeiführte, so bewirkte der Mord an Osiris die Erschaffung der Unterwelt. Mit dem Tod kamen die Toten in die Welt, für die neben Himmel (für die Götter) und Erde (für die Menschen und anderen Lebewesen) ein dritter Bereich geschaffen werden musste. Darauf spielt ein Text an, der als 175. Spruch ins Totenbuch aufgenommen wurde:

${ }^{23}$ Ibd., 1463a-e.

${ }^{24}$ Ibd., 1466a-67a. 
(Atum berät sich mit Thot, dem Gott der Schrift und der Weisheit) was nun $\mathrm{O}$ Thot, was ist es, das mit den Kindern der Nut geschehen soll? Sie haben Streit angefangen und Aufruhr erregt, sie haben Unrecht begangen und Empörung geschaffen, sie haben Gewalttat verübt und Gefangenschaft verursacht, sie haben Großes zu Kleinem gemacht in allem, was ich geschaffen habe. Gib doch wirksame Hilfe, o Thot! so sprach Atum.

Damit sind vermutlich der „Zorn“, der „Lärm“, die „Störung“, die „Furcht um das Horusauge" gemeint, von der die oben zitierten Pyramidentexte sprechen. Thot rät dem Schöpfer:

Du sollst dem Unrecht nicht zusehn und sollst es nicht dulden ihre Jahre sollen verkürzt sein, ihre letzten Monate herankommen, weil sie alles, was du geschaffen hast, im Verborgenen gestört haben.

In diesem Rat steckt die Quintessenz der politischen Theologie der Ägypter. Darauf werden wir im nächsten Abschnitt eingehen, der sich dem politischen Aspekt der Kosmogonie als „Kratogonie“ widmet. In unserem Text ergreift nun Osiris das Wort:

(Osiris spricht)

O Atum, was soll es,

dass ich zur Wüste des Totenreichs dahineilen soll?

Sie hat kein Wasser, sie hat keine Luft, sie ist ganz tief, ganz finster, ganz unendlich!“

Osiris, der von Seth erschlagene Gott, für den Atum das Totenreich geschaffen hat, ist von verständlicher Sorge erfüllt. Atum sucht ihn zu beruhigen:

Atum:

Du lebst dort in Frieden des Herzens.

Osiris:

Aber dort lässt sich ja keine Wollust finden.

Atum:

Ich habe Verklärtheit gegeben an die Stelle von Wasser, Luft und Wollust, und Frieden des Herzens an Stelle von Brot und Bier.

So werden auch Tod und Totenreich in die Schöpfungsordnung integriert und die Krise überwunden, die die „Kinder der Nut" heraufbeschworen haben. Jeder Tote wird Osiris nachfolgen und seinen Platz in dieser Ordnung finden. 
Das ist in großen Zügen die traditionelle ägyptische Vorstellung von der Weltentstehung, die in der Fülle der Texte zahlreiche zeitliche und lokale Abwandlungen erfährt, aber in ihren allgemeinen Umrissen eine erstaunlich konstante Geltung besaß. Zusammenfassend möchte ich folgende Besonderheiten noch einmal hervorheben:

1. Die Vorstellung des „kosmogonischen Augenblicks“ als dem „Ersten Mal“, als der im Akt der Selbstentstehung zum Sonnengott gewordene Urgott der Präexistenz zum ersten Mal aus dem Urwasser auftauchte. Dieser entscheidende Akt ist also weder eine „creatio ex nihilo“, noch die Überwindung eines vorhergehenden Chaos. Vor der Welt war nicht das Nichts, sondern das Urwasser (das in späteren Texten in eine Achtheit von Chaosaspekten ausdifferenziert wird) und der spätere Schöpfergott selbst war bereits im Zustand der Präexistenz, als Atum, in diesem Urwasser und trug die ganze Welt im Zustand des Noch-Nicht-Seins bereits in sich, die später aus ihm hervorgehen sollte.

2. Die Fortexistenz des Urwassers in der entstandenen Welt. Das ist eine für das ägyptische Weltbild absolut zentrale Vorstellung. Die Urmaterie, aus der die Welt entstand, ist mit der Kosmogonie nicht verschwunden bzw. in Welt umgesetzt, sondern weiterhin gegenwärtig, so dass die Sonne jeden Morgen aufs Neue aus dem "Urwasser" aufsteigt und jeder Sonnenaufgang dadurch zu einer Wiederholung des „Ersten Males“ wird. Das Urwasser umgibt als Ringozean die Erde und ist als Grundwasser unter der Erde gegenwärtig. Auch die Nilüberschwemmung entströmt dem Urwasser. So hat auch der Mensch Zugang zur Urmaterie, was die ägyptischen Vorstellungen von menschlicher Kreativität ganz entscheidend beflügelt hat. Er kann mit dem Wasser kosmogonische Energien freisetzen, die er vor allem im Totenkult einsetzt. Aus dem Fortbestehen der Urmaterie und der allmorgendlichen Wiederholung des Ersten Males folgt

3. das Fehlen eines Schlussstrichs, eines siebten Tages wie in der Bibel. In Ägypten hört die Schöpfung nicht auf, sondern geht immer weiter und ereignet sich jeden Morgen aufs Neue. Die Welt wird daher nicht als ein irgendwie abgeschlossener, vollendeter „Bau“ aufgefasst, wie es uns von der abendländischen und biblischen Tradition her vertraut ist, sondern als ein Prozess, dessen „kosmischer“, d.h. geordneter Charakter in seinem fortwährenden Gelingen besteht. Dieses Gelingen freilich steht nach ägyptischer Auffassung ständig auf dem Spiel. In dieser Hinsicht ist die ägyptische Idee der Weltentstehung die genaue Umkehrung der verbreiteten Vorstellung, dass die Welt in dramatischen transformativen Prozessen entstand, aber nun in geordneten Bahnen verläuft. Für die Ägypter entstand die Welt in widerstandsloser Selbstentfaltung des Urgottes, hat sich aber in der Gegenwart gegen den Widerstand des Bösen durchzusetzen, 
der eine ständige Gravitation zum Chaos ausübt. Schöpfung bedeutet in der entstandenen Welt die Durchsetzung der Ordnung gegen die Gravitation des Chaos. Im nächsten Abschnitt werden wir sehen, dass in diesem Punkt Schöpfung und Herrschaft identisch sind.

In diesem Schöpfungswerk der Weltinganghaltung sind die Menschen zur Mitwirkung aufgefordert. Darin liegt der entscheidende Punkt für unsere Frage nach der Kreativität. Die Menschen engagieren sich in der Form der Riten an dieser Aufgabe. Kann rituelles Handeln kreativ sein? Wir verbinden mit dem Begriff der Kreativität Innovation, im Gegensatz zu Repetition und Reproduktion. Reproduktives Handeln wird eben darum als nicht-kreativ eingestuft. Das hängt damit zusammen, dass uns der Sinn für rituelles Handeln völlig abhanden gekommen ist. Die Ägypter haben mit den Riten die Vorstellung äußerst bedeutungsvollen, chaosabwendenden, weltinganghaltenden Handelns verbunden. Die Riten griffen ihrer Vorstellung nach in die kosmogonischen Prozesse selbst ein, indem sie sich die in der Welt fortwirkenden kosmogonischen Energien und Materien zunutze machten. So wie heutige Astronomen im kosmischen Hintergrundrauschen das Echo des Urknalls vernehmen und in der rasant auseinander strebenden Struktur des Universums das Fortwirken der Urexplosion beobachten, so erfuhr der Ägypter das Fortwirken der kosmogonischen Energien im Zyklus von Tag und Nacht und der scheinbaren Bewegung der Sonne um die Erde, die er als ein gewaltiges, weltinganghaltendes, Ordnung schaffendes und Chaos abwendendes Handeln deutete.

\section{Kosmogonie und „Kratogonie“}

Die Theogonie der ersten Göttergenerationen lässt sich sowohl als eine Kosmogonie als auch eine Sukzession der Herrschaft von einer Generation auf die andere lesen. Der Schöpfer war zugleich der erste Herrscher. Nachdem er in spontaner Selbstentstehung entstanden war, bedeutete seine weitere, nach außen, auf die Welt hin gerichtete Schöpfertätigkeit zugleich die Ausübung von Herrschaft.

Von dieser Herrschaft erzählt der ägyptische Mythos von der Himmels$k u h$. In der Urzeit herrschte der Schöpfer als Sonnengott über eine Welt, in der Himmel und Erde noch nicht getrennt waren und Götter und Menschen zusammen lebten. Er war aber alt geworden, und so nutzten die Menschen seine Schwäche aus, um gegen ihn Ränke zu schmieden. Als der Sonnengott das merkte, beschloss er, das Menschengeschlecht insgesamt zu vernichten und beauftragte seine Tochter Tefnut damit, in ihrer Gestalt als Sachmet, die löwengestaltige Göttin der Seuchen, die Menschen auszurotten. Tags darauf jedoch reute ihn dieser Entschluss, und so machte er Sachmet trunken, um sie von ihrem Vorhaben abzubringen. So wurden die Menschen verschont, 


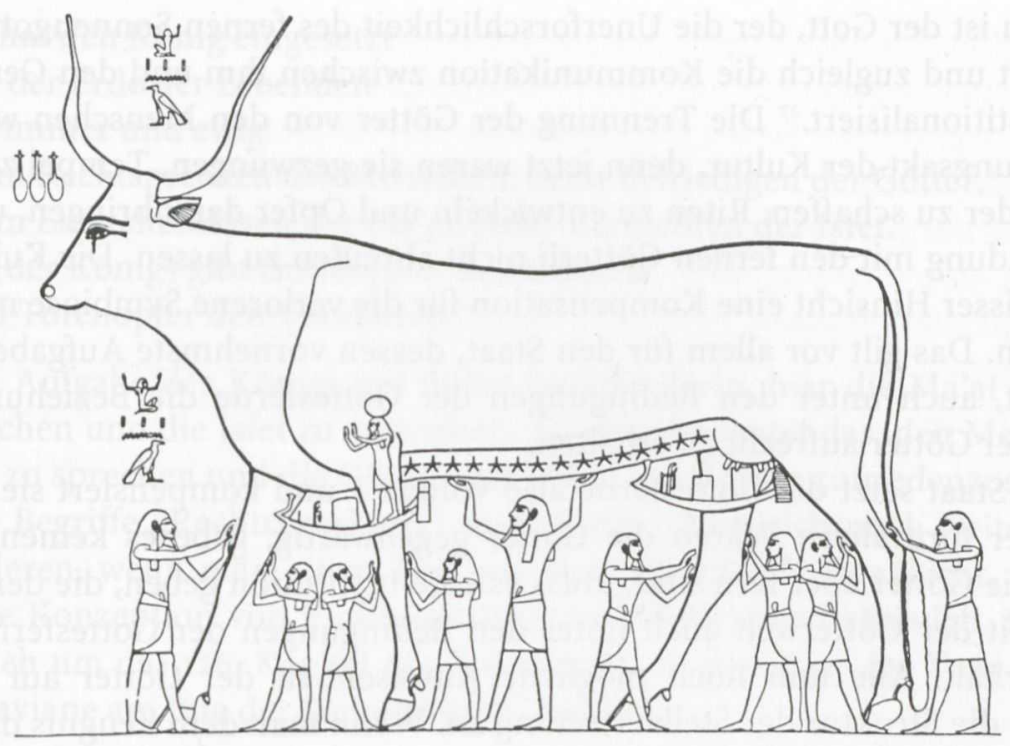

Abb. 4. Die Himmelskuh, von Schu gestützt. Äußerer Schrein Tutanchamuns [3]

aber der Sonnengott war es leid geworden, mit ihnen zusammen zu sein. Er trennte Himmel und Erde und zog sich mit den anderen Göttern in den Himmel zurück. Dieser Rückzug an den Himmel wird von da an die stehende Wendung für den Tod eines Herrschers sein. Die ägyptischen Könige sterben nicht, sondern sie "fliegen zum Himmel auf".

Auf der Erde aber setzte der Sonnengott seinen Sohn, den Luftgott Schu, als Nachfolger ein. ${ }^{25}$ Schu hat als Personifikation des Staates die Aufgabe, den Himmel hoch über die Erde emporzustemmen und damit zugleich die Gottesferne als auch die Verbindung zwischen Göttern und Menschen aufrechtzuerhalten. Indem er den Himmel fern hält, wirkt er zugleich als Mittler zwischen Himmel und Erde. Von diesem Gott heißt es in einem Text aus dem Anfang des Mittleren Reichs:

Ich bin es, der den Schrecken vor ihm (dem Sonnengott) denen einflößt, die nach seinem Namen forschen.

Ich bin es, der inmitten der Millionen ist und die Reden hört der Millionen.

Ich bin es, der die Worte des Selbstentstandenen (Sonnengottes) gelangen lässt zu seiner Menge (= Geschöpfen). ${ }^{26}$

${ }^{25}$ Hornung, Mythos von der Himmelskuh; Beinlich, Das Buch vom Fayum, 314-319.

${ }^{26}$ CT I, 322-324. 
Schu ist der Gott, der die Unerforschlichkeit des fernen Sonnengottes garantiert und zugleich die Kommunikation zwischen ihm und den Geschöpfen institionalisiert. ${ }^{27}$ Die Trennung der Götter von den Menschen war der Gründungsakt der Kultur, denn jetzt waren sie gezwungen, Tempel zu bauen, Bilder zu schaffen, Riten zu entwickeln und Opfer darzubringen, um die Verbindung mit den fernen Göttern nicht abreißen zu lassen. Die Kultur ist in gewisser Hinsicht eine Kompensation für die verlorene Symbiose mit den Göttern. Das gilt vor allem für den Staat, dessen vornehmste Aufgabe darin besteht, auch unter den Bedingungen der Gottesferne die Beziehung zur Welt der Götter aufrecht zu erhalten.

Der Staat setzt die Gottesferne also voraus - und kompensiert sie. Noch schärfer formuliert: Wären die Götter gegenwärtig, gäbe es keinen Staat. Weil die Götter aber fern sind, muss es eine Institution geben, die den Kontakt mit der Götterwelt auch unter den Bedingungen der Gottesferne aufrechterhält. Alle nun noch mögliche Anwesenheit der Götter auf Erden nimmt die Struktur der Stellvertretung an. Wenn man dem Zeugnis der Mythen folgt, dann wussten sich schon die alten Ägypter in einer vergleichsweise entzauberten Welt. Die Mythen stellen den gegenwärtigen Zustand ( status, „Staat") in das Licht einer Geschichte, die ihn als Heilung eines Bruchs und Kompensation eines Verlustes erklärt, nämlich des Verlusts von leibhaftiger Gottesnähe oder unmittelbarer „Realpräsenz“. An die Stelle der Realpräsenz treten Mittelbarkeit und Repräsentation. Staat und Kult, Tempel, Riten, Statuen, Bilder vermögen durch die Kraft des Symbols das Göttliche $\mathrm{zu}$ vergegenwärtigen und einen immer nur mittelbaren Kontakt mit dem Göttlichen zu stiften. Anstelle der ursprünglichen unmittelbaren und symbiotischen Gottesnähe, wie sie die Mythen erzählen und imaginieren, entsteht der kulturell geformte, auf den Möglichkeiten symbolischer Vermittlung und Vergegenwärtigung beruhende Raum der Gottesnähe. Der Staat ist die Institution dieser Gottesnähe. Der Pharao herrscht als Repräsentant des Schöpfergottes. Davon handelt ein „kulttheologischer Traktat ${ }^{\text {“ }}{ }^{28}$ über den König als Anbeter des Sonnengottes. Die letzte Strophe lautet:

${ }^{27}$ Es handelt sich, genau genommen, um indirekte oder Fern-Kommunikation, im Unterschied zu unmittelbarer oder face-to-face-Kommunikation. Schu personifiziert das Medium dieser Fern-Kommunikation, vermittelst dessen sie auch über große Entfernungen gelingen und den Zusammenhang der Millionen untereinander sowie mit ihrem Schöpfer und Herrn sicherstellen kann. Dahinter steht die Erfahrung der Schrifterfindung als notwendiger Vorbindung zur Bildung des ägyptischen Staates. Der durch Zentralisierung der Macht hergestellte und aufrechterhaltene Staat bedarf der symbolischen Integration in der Form politischer Kommunikation und bürokratischer Verwaltung.

${ }^{28}$ Vgl. hierzu Verf., Re und Amun, $24 \mathrm{ff}$. 
Re hat den König eingesetzt

auf der Erde der Lebenden

für immer und ewig

beim Rechtsprechen der Menschen, beim Befriedigen der Götter,

beim Entstehenlassen der Ma'at, beim Vernichten der Isfet.

Er (der König) gibt Gottesopfer den Göttern

und Totenopfer den Verklärten.

Die Aufgabe des Königs auf Erden besteht darin, hier die Ma'at zu verwirklichen und die Jsfet zu vertreiben. Konkret bedeutet das, den Menschen Recht zu sprechen und die Götter und Toten mit Opfern zufriedenzustellen.

Die Begriffe „Rechtsprechung“ und „Kult" lassen sich noch weiter konkretisieren, wenn man einen Text aus dem Totenbuch heranzieht, der die gleiche Konzeption von Repräsentation und Mittlertum behandelt. Es handelt sich um das 126. Kapitel des Totenbuchs, in dem sich der Tote an „die vier Paviane am Bug der Sonnenbarke" wendet,

die die Ma'at aufsteigen lassen zum Allherrn,

die Recht sprechen zwischen dem Schwachen und dem Starken,

die die Götter befriedigen mit dem Hauch ihres Mundes,

die den Göttern Gottesopfer

und den Verklärten Totenopfer geben. ${ }^{29}$

Dieser Text ersetzt die lapidaren Formeln „den Menschen Recht sprechen" und „die Götter befriedigen" durch die etwas ausführlicheren Wendungen „Recht sprechen zwischen dem Schwachen und dem Starken“ und „die Götter befriedigen mit dem Hauch ihres Mundes“ (der Rezitation heiliger Formeln). Mir kommt es vor allem auf die erste Formel an. Sie verweist auf das ägyptische Konzept der Gerechtigkeit als einer rettenden Herstellung von Gleichheit in einer Welt der Ungleichheit, in der es nicht nur Schwache und Starke gibt, sondern in der die Starken die Schwachen unterdrücken, wenn der Staat nicht eingreift.

Dieser Text ist aber auch deshalb wichtig, weil er die Themen der „rettenden Gerechtigkeit“ und der Repräsentation verbindet. Die Paviane erscheinen hier genau wie der König und der Gott Schu in der oben zitierten Passage aus den Sargtexten als Instanzen der Gerechtigkeit und der Kommunikation. Sie erhalten in einer weit und komplex gewordenen Welt die Verbindung zwischen oben und unten aufrecht. Sie lassen „die Ma'at aufsteigen " und verbreiten sie nach unten. Sie sorgen dafür, dass auch in der Situation der Ferne und Trennung Gemeinschaft erhalten bleibt und auch in einer Welt der Habgier und Gewalt die Schwachen versorgt sind.

${ }^{29}$ Pap. Nu, pBM 10477, col. 24 nach Budge, The Book of the Dead, 269 (Übersetzung J.A.) 
Der Sinn des Staates und des politischen Handelns wird als Abwendung von "Chaos" verstanden und dieses Chaos wird als Inbegriff des Bösen dargestellt. Wir dürfen diesen Begriff des Chaos jedoch nicht mit dem kosmogonischen Chaos verwechseln, dem Urzustand der Vorwelt, aus dem die Ordnung der Schöpfung hervorgeht. Das kosmogonische Chaos, ägyptisch Nun, ist eine ungeschiedene Urmaterie, der alle Konnotationen des Bösen oder Unvollkommenen (wie sie etwa im biblischen „Tohuwabohu“ mitschwingen) abgehen. Das Chaos, zu dessen Abwendung das Mittlere Reich angetreten ist, gehört nicht in den kosmogonischen, sondern in den „kratogonischen" Diskurs. Nicht die Entstehung von Welt, sondern die Errichtung von Herrschaft hat sich mit diesem Chaos auseinanderzusetzen.

Die Kosmogonie ist für den Ägypter ein komplexer Prozess, der die beiden Aspekte intransitiver Entfaltung und transitiver Schöpfung miteinander verbindet. Die Kratogonie jedoch, die Entstehung der Herrschaft, in deren Formen der Schöpfer die entstandene Welt erhält, ist eindeutig transitiv. In diesen Zusammenhang gehört die Vorstellung vom Bösen. Ihm tritt der Schöpfer in der Gestalt des Sonnengottes entgegen und tritt selbst mit den tödlichen Insignien des Königtums auf. Auch der Sonnengott muss die lebensspendende, Ordnung und Frieden, Sicherheit und "Sinn“ gewährende Gerechtigkeit, die er mit seinem Licht verbreitet, gegen die allgegenwärtige Bedrohung des Bösen durchsetzen, der sie in der Gestalt eines riesigen Wasserdrachens bedroht. ${ }^{30}$ Dieses dramatische Weltbild verlängert die ideologischen Grundlagen des ägyptischen Staates ins Kosmische. So erscheint dann der Staat als die Verlängerung des kosmischen Schöpfungs- und Inganghaltungswerkes ins Irdisch-Politische.

Der Mythos von der Vernichtung des Menschengeschlechts im Buch von der Himmelskuh deutet diese Unvollkommenheit, wie die meisten anderen Religionen auch, durch eine Urverschuldung der Menschen, die gegen den Schöpfer rebelliert haben. Der Mythos ist aber keineswegs die einzige Form, in der sich die Ägypter mit der Erfahrung des Bösen auseinandergesetzt haben. Von der Rebellion der Menschen ist auch in der Lehre für Merikare die Rede. Dieser Text ist in unserem Zusammenhang von zentraler Bedeutung. Er verbindet die Erfahrung des Bösen mit dem Postulat der wohlgeordneten und wohlversorgten Welt:

Wohlversorgt sind die Menschen, die Herde Gottes.

Ihretwegen schuf er Himmel und Erde, drängte er die Gier des Wassers zurück und schuf die Luft, damit ihre Nasen leben.

Seine Ebenbilder sind sie, aus seinem Leib hervorgegangen.

${ }^{30}$ Vgl. hierzu Brunner, „Seth und Apophis“, 226-234. 
Ihnen zuliebe geht er am Himmel auf,

für sie erschuf er die Pflanzen und die Tiere,

Vögel und Fische, damit sie zu essen haben.

Weil sie (aber) auf Rebellion sannen,

tötete er seine Feinde und gebrauchte Gewalt gegen seine Kinder.

Ihnen zuliebe lässt er es Licht werden,

um sie zu sehen, fährt er (am Himmel) dahin.

$\mathrm{Zu}$ ihrem Schutz errichtete er sich eine Kapelle;

wenn sie weinen, dann hört er.

Er schuf ihnen Herrscher, im Ei ${ }^{`}$

und Befehlshaber, um den Rücken des Schwachen zu stärken.

Er schuf ihnen Zauber als Waffe,

um den Schlag des Geschehenden abzuwehren,

wachend über sie des Nachts wie am Tage.

Dass er die ,Krummherzigen' erschlug unter ihnen,

war wie ein Mann seinen Sohn schlägt um seines Bruders willen.

Gott kennt jeden Namen.

Der Text zählt zwölf Werke des Schöpfers auf. Zehn davon sind eigens zum Wohle der Menschen ergangen und dieses „um ihretwillen“ oder „für sie" wird für jede einzelne dieser Taten ausdrücklich wiederholt. Zwei jedoch, bei denen dieses „für sie“ fehlt, sind gegen sie gerichtet im Sinne der strafenden, richterlichen Gewalt. Er hat einen Unterschied gemacht zwischen ihnen: den Unterschied zwischen gut und böse. Die Bösen hat er erschlagen; nicht „um ihretwillen“, sondern um der Guten willen. Dieser Text bezieht sich auf das gleiche Thema - und das heißt: die gleiche Erfahrung wie der Mythos von der Zerstörung des Menschengeschlechts. Genau wie in diesem Mythos werden auch hier die Einrichtung des Staates („Herrscher im Ei“) und des Zaubers als kompensatorische Maßnahmen des Schöpfers gedeutet, um in der vom Bösen gefährdeten Welt eine Sphäre der Ordnung und Wohlversorgtheit zu gewährleisten. Ohne den Staat wären der Schwache und ohne Magie der von Unheil Bedrohte verloren. Die strafende Gewalt, die der Schöpfer gegen seine eigenen Kinder richtet, ist unabdingbare Voraussetzung ihrer Wohlversorgtheit. Sie geschieht nicht blind und hat nichts zu tun mit dem „Schlag der Ereignisse“, zu dessen Abwendung den Menschen die Magie gegeben wurde. Den Schlag Gottes kann auch die Magie nicht abwehren. Der „Schlag der Ereignisse“ ist sinnlos oder kontingent und liegt außerhalb des Horizonts der konnektiven Gerechtigkeit. Der Schlag Gottes aber ist sinnvoll. Er wird ausdrücklich begründet. „Weil sie auf Rebellion sannen“ erschlug er seine Kinder, „wie ein Mann (d.h. ein Vater) seinen eigenen Sohn um dessen Bruder willen schlägt“, tötete er die „Krummherzigen" unter ihnen. 
Damit befolgt der Schöpfer den Rat, den ihm Thot im 175. Totenbuchkapitel gibt: „Du sollst dem Unrecht nicht zusehn und sollst es nicht dulden!“ Hinter dieser Einsicht stehen die Erfahrungen, die die Ägypter nach dem Zusammenbruch des Alten Reichs gemacht haben, als der Staat zusammengebrochen war. Von diesen Erfahrungen handeln Texte, die aus späterer Zeit auf diese Epoche zurückblicken, um (in zweifellos propagandistischer Absicht) die Lebensnotwendigkeit staatlicher Ordnung einzuschärfen. Aber in ihrer Darstellung sind es nicht die "Krummherzigen“, die erschlagen werden, sondern die Schwachen, die Wenigen, die Kinder, die keine Schuld an ihrem Schicksal tragen, ebenso wenig wie die Menschen, die Hungers sterben. In einem dieser Texte, den Mahnworten des Ipuwer, wird dem Schöpfer der Vorwurf gemacht, dass er dem Unrecht zusieht und es duldet. Dieser Vorwurf an Gott liest sich als die genaue Umkehrung dieses Hymnus auf die Schöpfungsordnung. Die Herde des Schöpfers ist alles andere als wohlversorgt. Vielmehr gilt: „Seine Herde ist gering“, weil die Menschen sich gegenseitig umbringen. Keineswegs greift Gott ein und schlägt seinen Sohn um dessen Bruders willen. Vielmehr gilt: „Der Furchtsame wird nicht unterschieden vom Gewalttätigen." Keineswegs wacht Gott über sie Tag und Nacht. Vielmehr gilt: „Es gibt keinen Lotsen zu ihrer Stunde. Wo ist er heute? Schläft er etwa? Man kann seine Macht nicht erkennen.“

Als wir in Trauer versetzt worden waren, konnte ich dich nicht finden.

Man konnte dich nicht anrufen, da du frei von Zorn bist darüber, und das bedeutet Leiden verursachen..$^{31}$

Dieser „Vorwurf an Gott“ gehört zu den erstaunlichsten Texten, die uns aus dem Alten Ägypten erhalten sind. Nicht weil die Menschen aufhörten, an Gott zu glauben, sondern weil Gott aufhörte, sich für die Menschen zu interessieren und über das von ihnen begangene Unrecht in Zorn zu geraten, brachen in der sozialen Welt die Ordnungen der Gerechtigkeit zusammen! Es gibt einen Text, den man oft als Antwort des Schöpfergottes auf diesen ungeheuren Vorwurf verstanden hat:

$\mathrm{Zu}$ sprechen von Dem mit Geheimem Namen.

Der Allherr sagte, als die Empörung gestillt werden mußte in der

Barkenmannschaft:

Seid heil und in Frieden!

Ich will euch die vier guten Taten verkünden,

die mir mein eigenes Herz getan hat in der Umringlerschlange,

um das Unrecht zum Schweigen zu bringen.

Ich habe vier gute Taten vollbracht im Portal des Lichtlands:

${ }^{31}$ Fecht, Vorwurf an Gott, S. $108 \mathrm{f}$. 
Ich habe die vier Winde geschaffen, damit jedermann atmen kann in seiner Zeit.

Das ist eine der Taten.

Ich habe die große Wasserflut geschaffen, damit der Arme darüber verfügen kann wie der Reiche.

Das ist eine der Taten.

Ich habe einen jeden seinem Nächsten gleich geschaffen und habe verboten, dass sie Unrecht tun sollten.

Aber ihre Herzen haben sich dem widersetzt, was ich befohlen habe.

Das ist eine der Taten.

Ich habe geschaffen, dass ihre Herzen aufhören, den Westen zu vergessen

(d.h. ich habe die Todesfurcht geschaffen)

damit den lokalen Göttern Opfer dargebracht würden.

Das ist eine der Taten.

(...)

Ich richte den Armen und den Reichen.

Ich gehe gleichermaßen vor gegen die, die Unrecht tun.

Mir gehört das Leben, ich bin sein Herr.

Niemand wird mich der Herrschaft berauben. ${ }^{32}$

Was der Sonnen- und Schöpfergott vorbringt, „um das Unrecht zum Schweigen zu bringen", ist die Affirmation des Prinzips Herrschaft. Das Chaos kommt aus dem menschlichen Herzen. Ihm steht das Verbot des Schöpfers entgegen. Der Sonnengott kann nicht verhindern, dass sein Verbot übertreten wird. Aber er kann und wird die Übertretung bestrafen. Er tötet um des Lebens willen. Er hält die Szepter des Lebens (das „Anch“Zeichen) und der Herrschaft (das „Was“-Szepter) in der Hand. „Nicht gibt es ein Ende des Tages des Gerichtes“. ${ }^{33}$

Das ist der Gott, den der König auf Erden repräsentiert. Der Staat setzt die lebensspendende und richtende Herrschaft des Schöpfergottes in irdische Verhältnisse um. Das Urbild und Modell legitimer Herrschaft ist die Herrschaft des Schöpfers über das von ihm Geschaffene. Schöpfung und Herrschaft gehören daher im ägyptischen Denken unauflösbar zusammen. Herrschaft ist nichts anderes als die Verantwortung des Schöpfers über das, was aus ihm hervorgegangen ist. Herrschaft ist Fortführung der Schöpfung in Form der Weltinganghaltung.

Die kreativen Implikationen dieses Schöpfungskonzepts treten sofort in aller Deutlichkeit hervor, wenn wir uns klarmachen, dass die Ägypter nicht

\footnotetext{
${ }^{32}$ Sargtext 1130 CT VII, 466-67.

${ }^{33}$ Buch vom Fayum ed. Horst Beinlich, $300 \mathrm{f}$.
} 
nur den ersten Großstaat der Menschheitsgeschichte geschaffen haben, sondern es überdies vermocht haben, diesen Staat über alle Zusammenbrüche hinweg immer neu zu errichten und selbst über die Zeiten der persischen, griechischen und römischen Fremdherrschaft hinweg als eine nicht nur politische, sondern auch kulturelle und religiöse Institution aufrechtzuerhalten. Die Ägypter haben ebenso wie die Griechen einen Großteil ihres schöpferischen Genies in die Errichtung politischer Ordnung investiert und dabei genau den umgekehrten Weg wie die Griechen eingeschlagen. Während bei den Griechen am Ende ihres politischen Schöpfertums die Polis steht als die Realisierung freier, „demokratischer“ Selbstverwaltung der Bürger eines Gemeinwesens, steht bei den Ägyptern die Form einer Monarchie, die sich als Stellvertretung des göttlichen Schöpfertums auf Erden und in der Menschenwelt versteht. Die Schattenseite der griechischen Polis ist die Dreiklassengesellschaft der freien Bürger, der "Metöken“ (in der Polis wohnende Fremde) und der Sklaven; die Schattenseite der pharaonischen Monarchie ist der starke Integrationsdruck, dem alle Untertanen dieses Staates als Steuerzahler, Arbeitsdienstpflichtige und bekennende Gefolgsleute Pharaos als eines Gottes auf Erden unterworfen sind, der auf der anderen Seite aber wenigstens theoretisch keine Klassenbildung innerhalb dieser Untertanenschaft zulässt, weil sich der Staat (was gerne verkannt wird, vor allem aufgrund der biblischen Polemik) als eine rettende, die sozialen Unterschiede kompensierende Institution zur Unterstützung der Schwachen versteht.

\section{Schöpfung durch das Wort. Sprachlichkeit und Lesbarkeit der Welt}

Die großartigste und für die Vorstellungen menschlicher Kreativität folgenreichste Schöpfungsvorstellung ist die Idee der Schöpfung durch das Wort. Diese Idee geht am weitesten hinaus über die kosmogonischen Konzeptionen, denen zufolge die Welt von selbst und ohne Intervention eines Weltschöpfers entsteht. Hier wird die Welt nicht nur durch einen Schöpfer geschaffen, sondern dieser Schöpfer bedient sich dazu eines Mittels, das mit der Natur gerade des Menschen auf besondere Weise zusammenhängt. Die Sprache ist nur dem Menschen zueigen und hebt ihn aus der Sphäre der anderen Geschöpfe heraus. So erfährt er sich in einer durch das Wort erschaffenen Welt als der Partner Gottes, der die göttliche Kreativität in seinem eigenen Sprechen und Verstehen erlebt. Uns ist die Vorstellung von der Schöpfung durch das Wort über den biblischen Schöpfungsbericht vertraut. Dort ist auch von dem korrespondierenden Schöpfertum des Menschen die Rede, denn Adam darf den übrigen Geschöpfen Namen geben, wie sie der Herr ihm zuführt. Gott „spricht“ in Geschöpfen, und der Mensch vermag diese Sprache zu verstehen und in „Namen“ seiner eigenen Sprache zu übersetzen. 
Auch in Ägypten spielt der Gedanke einer Schöpfung durch das Wort eine große Rolle. Er ist dort nicht von Anfang an greifbar, sondern entwickelt sich im Laufe der Jahrhunderte. Dabei wird er zunächst nur in Bezug auf die Götter angewandt. Von ihnen heißt es immer wieder, dass sie „aus dem Munde" der Gottes kamen, während die Menschen „aus seinem Auge“ hervorgingen. ${ }^{34}$

Du bist der Eine, der alles Seiende geschaffen hat, der Eine Einsame, der schuf, was ist.

Die Menschen gingen aus seinen Augen hervor, und die Götter entstanden aus seinem Mund. ${ }^{35}$

Diese Lehre vom Ursprung der Menschen beruht auf dem Gleichklang der ägyptischen Worte für „Träne“ und „Mensch“, berührt sich aber auch auf eigentümliche Weise mit der orphischen ${ }^{36}$ und auch sonst in griechischen Texten belegbaren Vorstellung ${ }^{37}$, dass die Götter aus dem Lachen, die Menschen aber aus den Tränen des Urgottes entstanden..$^{38}$

Schon in Texten des 13. Jhs. aber wird dieser Gedanke vom Ursprung der Götter auf die gesamte Schöpfung ausgeweitet:

der Himmel und Erde erschuf und die Menschheit gebar, der alles Seiende hervorbrachte mit dem Ausspruch seines Mundes.

Der sprach, und es geschah, der das Existierende gebar, Großer, Schöpfer der Götter und Menschen.

Der allein entstand und sich gebar als Millionen

Seine Glieder waren es, die antworteten,

seine Zunge war es, die alles bildete, was er erschuf. ${ }^{39}$

Der ägyptische Text, der diesen Gedanken am konsequentesten ausarbeitet, ist das „Denkmal memphitischer Theologie“. ${ }^{40}$ Dabei handelt es sich um einen Basaltblock der 25. Dynastie (Ende 8. Jh. v. Chr.), dessen Inschrift sich

${ }^{34}$ S. dazu Verf., Re und Amun, 235-238.

35 ÄHG Nr. 87, Verse 107-110.

${ }^{36}$ Orphicorum fragm. 28 Abel.

37 Dieterich, Abraxas, 28.

${ }^{38}$ So auch in einem ägyptischen Hymnus aus Esna (Nr. 272, 2-3) s. S. Sauneron, Les fêtes religieuses, 142 .

39 ÄHG Nr. 106.

$4^{0}$ Der Text ist erstmals im Jahre 1902 von Breasted als „Philosophy of a Memphite Priest“ bekannt gemacht worden. Erman hat ihm 1909 unter dem Titel Ein Denkmal memphitischer Theologie eine kommentierte Übersetzung gewidmet, die dem Text bis heute seinen Namen gegeben hat. Die maßgeblichen Editionen stammen von Sethe, Dramatische Texte und H. Junker, Die Götterlehre von Memphis, und Die politische Lehre von Memphis. Wichtige neuere Behandlung bei J.P. Allen, Genesis in Egypt., 42-47. Ich zitiere das „Denkmal memphitischer Theologie" im Folgenden nach Junker. 
als Wiedergabe einer alten Papyrushandschrift ausgibt. In der Überschrift erklärt König Schabaka die Umstände der Redaktion:

„Seine Majestät ließ dieses Buch von neuem schreiben im Hause seines Vaters Ptah. Seine Majestät hatte es nämlich gefunden als Werk der Vorfahren, von Würmern zerfressen, und man kannte es nicht vom Anfang bis zum Ende. Da ließ es S.M. von neuem schreiben, sodass es schöner ist als es vordem war."

Früher stritt man darum, ob der Text eher in die 1.-2. oder in die 5.-6. Dynastie gehört. ${ }^{41}$ Inzwischen sind viele gute Gründe dafür beigebracht worden, dass er zumindest in Teilen wenn nicht überhaupt als Ganzes ein Werk der 25.Dynastie darstellt. ${ }^{42}$ Seine Datierung schwankt also um fast 2500 Jahre!

In diesem Text erfährt das Motiv der Präexistenz eine Ausdeutung, nach der die Aspekte des Chaos ihrerseits aus dem Gott Ptah hervorgegangen sind, wobei die ägyptische Wendung hpr $m$ sowohl „entstehen aus" als auch

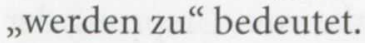

Die Götter, die aus Ptah entstanden/zu Ptah geworden sind:

Ptah auf dem Großen Thron [...]

Ptah Nun

Ptah Naunet

Ptah-Wer

$[\ldots]$

$[\ldots]$

$[\ldots]$

$[\ldots]$
Der Vater, der Atum [zeugte]

Die Mutter, die Atum gebar

Das sind Herz und Zunge der Neunheit

[...] alles ... der die Götter gebar

[...] .... der die Götter gebar

$[\ldots]$

[... Nefer]tem an der Nase des Re,

Tag für Tag,

entstanden durch das Herz als Sinnbild des Atum, entstanden durch die Zunge als Sinnbild des Atum, indem es groß und gewaltig war. ${ }^{43}$

Wie immer man diesen sehr zerstörten Textabschnitt ergänzen will - eines ist klar: auch der präexistente Urzustand wird noch einmal transzendiert auf einen Gott hin, der damit als die schlechthin transzendente, auch der Präexistenz noch voraus- und zugrundeliegende Einheit dargestellt wird. Dann heißt es von Ptah weiter:

${ }^{41}$ Für die Frühzeit plädierte insbesondere K. Sethe, für das hohe Alte Reich H. Junker.

${ }^{42}$ F. Junge, „Zur Fehldatierung des sog. Denkmals memphitischer Theologie“.; H.A. Schlögl, Der Gott Tatenen.

${ }^{43}$ Zeilen 48-53 s. Junker, 16 f. und 39. Der erste Akt der Schöpfung, auf den hier resümierend zurückgeblickt wird, ist die Entstehung der Götterwelt. Die herkömmliche Übersetzung "groß und gewaltig ist Ptah" ist ungrammatisch und semantisch nichtssagend. 
Ptah überwies [Leben allen Göttern] und ihren Kas durch dieses Herz, aus dem Horus, und durch diese Zunge, aus der Thot entstand aus Ptah.

So geschah es, dass das Herz und die Zunge Verfügungsgewalt erhielten über alle anderen Glieder

aufgrund der Lehre, dass es (das Herz) jedem Leib und sie (die Zunge) jedem Mund vorsteht

von allen Göttern, allen Menschen, allen Tieren und allem Gewürm, das da lebt indem (das Herz) alles denkt und (die Zunge) alles befiehlt, was sie wollen. Seine Neunheit war vor ihm als Zähne, d.i. der Same des Atum und als Lippen, d.i. die Hände des Atum.

Es war ja die Neunheit des Atum entstanden durch seinen Samen und durch seine Finger.

Die Neunheit aber ist in Wahrheit Zähne und Lippen in diesem Munde dessen, der die Namen aller Dinge erdacht hat, aus dem Schu und Tefnut hervorgegangen sind, der die Neunheit geschaffen hat.

Dass die Augen sehen, die Ohren hören und die Nase Luft atmet, ist, um dem Herzen Meldung zu erstatten.

Dieses ist es, das alle Erkenntnis entstehen lässt.

Die Zunge ist es, die wiederholt, was vom Herzen gedacht wird. ${ }^{44}$

"Phallus“ und „Hand“, die überlieferten Körpersymbole der Kreativität, werden als „Zähne und Lippen“ gedeutet. Die eigentlich kreativen Organe sind Herz und Zunge. Da der Ägypter keine scharfe Grenze zwischen „Körper" und Geist" zieht, werden auch Erkenntnis und Sprache als körperliche Phänomene verstanden. Die Erkenntnis entsteht im Herzen aufgrund der ihm gemeldeten Sinnesdaten. Die im Herzen geformte Erkenntnis wird von der Zunge artikuliert. Dabei wird deutlich hervorgehoben, dass die kreativen Organe des Schöpfergottes in jedem der von ihm geschaffenen Lebewesen lebendig sind.

Die memphitische Interpretation der heliopolitanischen Kosmogonie setzt am Mysterium des kosmogonischen Augenblicks an. "Same“ und „Hände“ werden als „Zähne“ und „Lippen“ interpretiert und damit das Bild der Masturbation ersetzt durch den Akt des Sprechens. Das Denkmal memphitischer Theologie unterscheidet sich in seiner Darstellung einer Schöpfung durch das Wort von der biblischen in zwei Punkten. Der eine ist die Rolle des Herzens, d.h. der planenden Konzeption der Schöpfung; davon

${ }^{44}$ Zeilen $53-55$ s. Junker, 39; 48; 55; 58. 
ist in der Bibel nicht die Rede. Der andere ist die Rolle der Schrift, der Hieroglyphen, die zweimal erwähnt wird. ${ }^{45}$ Diese beiden Punkte hängen eng miteinander zusammen. Denn was das Herz ersinnt, ist nicht die Lautgestalt der Dinge, sondern ihr „Begriff" und ihre „Form“. Die Hieroglyphenschrift gibt diese Form wieder und bezieht sich auf dem Weg über die Form auf den Begriff. Die Zunge vokalisiert die Begriffe, die vom Herzen erdacht und von der Hieroglyphenschrift in sichtbare Form gebracht werden:

Und so wurden alle Götter geboren, das ist Atum und seine Neunheit.

Es entstanden aber alle Hieroglyphen

durch das, was vom Herzen erdacht und von der Zunge befohlen wurde.

Und so wurden alle Handwerke geschaffen und alle Künste, das Handeln der Arme und das Gehen der Beine, die Bewegung aller Glieder gemäß seiner Anweisung dieser Worte, die vom Herzen erdacht und von der Zunge geäußert wurden und die die Versorgung von allem schaffen.

$\cdots$

So wurde gefunden und erkannt, dass seine Kraft größer ist als die aller anderen Götter.

Und so war Ptah zufrieden, nachdem er alle Dinge erschaffen hatte ${ }^{46}$ und alle Hieroglyphen, nachdem er die Götter gebildet hatte, nachdem er ihre Städte geschaffen und ihre Gaue gegründet hatte, nachdem er ihre Opferkuchen festgesetzt und ihre Kapellen gegründet hatte, nachdem er ihre Leiber ihnen gleich gebildet hatte, sodass sie zufrieden waren.

Und so traten die Götter ein in ihren Leib

aus jeglicher Art Holz und Mineral, jeglichem Ton und allen anderen Dingen, die auf ihm wachsen, aus dem sie entstanden sind.

Und so versammelten sich um ihn alle Götter und ihre Ka's zufrieden und verbunden im Herrn der beiden Länder. ${ }^{47}$

$45 m d w n t \underline{t} r$, wörtlich "Gottesworte“, ist die ägyptische Bezeichnung der Hieroglyphenschrift.

${ }^{46}$ Man könnte auch htp geradezu übersetzen „und so ruhte...“, in Entsprechung zum biblischen Schöpfungsbericht. Aber der Begriff der Arbeitsruhe (Pause) wird im Ägyptischen anders ausgedrückt.

47 Zeilen 56-61; s. Junker, 59;62; 63; 65; 66. 
Ptah ist der Gott der Künstler und Handwerker; ihm verdanken die Dinge ihr „design“, die ihre unveränderliche, im Werden und Vergehen der Dinge und Lebewesen ewig reproduzierte und im Schriftzeichen abgebildete Gestalt. Thot, der Gott der „Zunge“, ist daher auch der Gott der Hieroglyphenschrift. Er vermag die Gedanken des Herzens in gesprochene und geschriebene Sprache umzusetzen. Die Schöpfung ist ein Akt der Artikulation: gedanklich, ikonisch und phonetisch. Mit den Dingen und ihren Namen entstehen zugleich auch ihre Schriftzeichen:

Und so war Ptah zufrieden, nachdem er alle Dinge erschaffen hatte und alle Hieroglyphen.

Die Gesamtheit der Schöpfung wird zusammengefasst in der Wendung „alle Dinge und alle Hieroglyphen“.

Das Motiv der „Schöpfung durch das Herz“ betont die planvolle Konzeption, die der Welt zugrunde liegt. Das wird gerade in Texten über den memphitischen Schöpfergott Ptah schon früher greifbar..$^{48}$ Von der Hieroglyphenschrift ist jedoch in diesen Texten kaum jemals die Rede. Hier handelt es sich um ein Spezifikum unseres Textes. Es ist zugleich sein „modernster" Zug. Denn diese Einschätzung der Hieroglyphenschrift kann erst zu einem Zeitpunkt aufgekommen sein, als sie sich zu einem rein sakralen Medium entwickelt hat: in der Spätzeit. Die Einschätzung der Hieroglyphenschrift als einer heiligen, priesterlichen Schrift, in der nur sakrale Texte geschrieben werden und die nur Priester eingeweiht sind, begegnet uns erst bei griechischen Autoren. Sie wird meist als ein Missverständnis abgetan, aber sie reflektiert auf eine sehr getreue Weise das Bild, das die ägyptischen Priester selbst sich von ihren Schriftsystemen machten und das sie den Griechen vermitteln wollten. ${ }^{49}$ In der Tat entwickelt sich erst in der Spätzeit die Hieroglyphenschrift zu einer Art Dingschrift, deren Zeichenrepertoire dem Gesamtbestand der Dinge koextensiv ist. Wo der Schabaka-Text auf diese Theologie Bezug nimmt, kann er nicht älter sein als die Ramessidenzeit. Es handelt sich dabei um dieselben Textteile, in denen von Ptah-Tatenen die Rede ist.

Wenn man die Unterscheidung zwischen einer Sphäre der Urbilder (Ideen) und einer Welt unendlich reproduzierter Abbilder als ein Prinzip der platonischen Philosophie identifizieren darf, dann kommt bereits in dieser Zweiteilung der Schöpfung ein ursprünglicher und untheoretischer Platonismus zum Ausdruck. Die Hieroglyphen sind die Urbilder der Dinge, die die Gesamtheit der Wirklichkeit ausmachen. Zwischen Ding und Schriftzei-

${ }^{48} \mathrm{Vgl}$ Verf., Re und Amun, 220-1; 230; 238-241.

49 Zur Gräko-ägyptischen Kultur der hellenistischen und römischen Zeit s. G. Fowden, The Egyptian Hermes. 
chen besteht im ägyptischen „hieroglyphischen“ Denken eine ähnliche Relation wie zwischen Ding und Begriff im griechischen. Indem Ptah die Urbilder der Dinge konzipierte, erfand er zugleich mit ihnen auch die Schrift, die Thot nur aufzuzeichnen braucht, so wie er die als Zunge die Gedanken des Herzens nur aussprechen muss. Ein Onomastikon ist daher überschrieben als Auflistung „aller Dinge, die Ptah geschaffen und Thoth niedergeschrieben hat" ${ }^{50}$ Thot, der Gott der Schrift, musste sie nur finden, nicht erfinden. Sie war schon in der Struktur der Wirklichkeit angelegt. Der Neoplatoniker Jamblich hat den latenten Platonismus des hieroglyphischen Denkens sehr scharfsinnig erkannt, wenn er in seinem Brief des Abammon das symbolische Schriftprinzip der Ägypter als eine Nachahmung der göttlichen „Demiurgie“ deutet: „Die Ägypter ahmen die Natur des Universums und die Demiurgie der Götter nach, indem sie mithilfe von Symbolen Bilder der mystischen, unsichtbaren und geheimen Begriffe erzeugen, in derselben Weise wie die Natur auf symbolische Weise die unsichtbaren Logoi in sichtbaren Formen ausdrückt und die göttliche Demiurgie die Wahrheit der Ideen in sichtbaren Bildern niederschreibt. ${ }^{51}$

Das Zusammenspiel von Ptah, der die Dinge „erschafft“ und Thot, der sie "niederschreibt“ erinnert an das Zusammenspiel von Gott und Adam im Paradies. Gott erschafft die Lebewesen „und führt sie Adam zu, um zu sehen, wie der sie nennen würde: Und wie immer er sie benannte, das war ihr Name." (Gen 2, 20). Adams Akt der Benennung und Thots Akt der Zuschreibung erfüllen beide dieselbe Funktion der Verknüpfung von Dingen und Worten, und da es sich um eine Schöpfung durch das Wort handelt, „lesen“ Adam und Thot den Dingen ab, was sie aussprechen bzw. niederschreiben.

Die Schöpfungslehre von Memphis betont die Schriftförmigkeit der Welt. Sie deutet die Welt als einen Text, den Ptah im Herzen erdacht und vermittelst der Zunge ausgesprochen hat, woraufhin er sich in der sichtbaren Wirklichkeit in Gestalt der Dinge realisiert hat, die den Hieroglyphen entsprechen. Dieser kühne Entwurf wird in ständiger Bezugnahme auf die heliopolitanische Lehre entfaltet.

Wenn wir diese Konzeption einer Schöpfung durch das Wort auf die Schrift beziehen, wird die Beziehung zu Vorstellungen menschlicher Kreativität sofort deutlich. In schriftgeschichtlicher Hinsicht bedeutete nämlich die Spätzeit in Ägypten, natürlich nach der Epoche der eigentlichen Schrifterfindung zu Ende des 4. Jahrtausends, eine Periode geradezu explosiver Kreativität und eine ausgesprochene Blütezeit. In der Zeit zwischen dem 6. Jh. v. Chr. und dem 2. Jh. nach Chr. wurde der überlieferte Bestand von ca. 700-1000 Zeichen auf über 7000 erweitert. Der Gedanke von der Schriftför-

\footnotetext{
${ }^{50}$ A.H.Gardiner, Ancient Egyptian Onomastica, $1^{*}$.

51 Iamblichus, De Mysteriis, VII.1.
} 
migkeit der Welt wurde umgesetzt in die Form einer Weltförmigkeit der Schrift, d.h. in den Versuch, den Bestand der Schriftzeichen und das Formenrepertoire der Welt zur Deckung zu bringen. Die hieroglyphischen Inschriften dieser Zeit bemühten sich, in ihrer Zeichenkomposition sowohl den Sprach- als auch den Weltbezug der Schrift herauszuarbeiten. Aus diesem „Beziehungszauber" entstanden hochkomplexe Schriftspiele, die auch unter den heutigen Ägyptologen nur wenige Spezialisten enträtseln können.

\section{Autonome und heteronome Weltmodelle}

Der entscheidende Unterschied zwischen den ägyptischen Vorstellungen von der Weltentstehung und dem biblischen Schöpfungsmythos liegt in dem Motiv des Schlussstrichs und der damit verbundenen Frage von der weiteren Erhaltung der geschaffenen Welt. In der Bibel schafft Gott die Welt in sechs Tagen und ruht sich am siebten Tage aus, um damit eine deutliche Zäsur zu setzen zwischen der Phase der Weltentstehung und der Dauer der Welterhaltung. Nachdem die Welt einmal geschaffen ist, muss sie von Gott nicht weiter in Gang gehalten werden. Sie bildet ein selbstregulierendes System; man könnte auch sagen, dass ihr von Gott die Geheimnisse ihres weiteren Funktionierens einprogrammiert sind, so dass die Gestirne ihre Bahnen kennen und die Winde wissen, wann und wohin sie zu wehen haben. Ihr weiterer Bestand hängt einzig allein von Gottes Willen ab, sie nicht wieder zu zerstören. Jedenfalls können und sollen die Menschen zu ihrem Gange nichts beitragen. Die Sonne geht auf und unter, ohne von den Menschen darin mit Opfern und Hymnen bestärkt zu werden, und dasselbe gilt für Mond und Sterne, Regen und Wind. Immer wieder wird der Mensch gewarnt, die Mächte der Natur nicht anzubeten, da sie nicht nur wie er selbst von Gott geschaffen sind, sondern weil er den Menschen zum Herrn der Erde eingesetzt hat. Das Prinzip des dominium terrae („macht euch die Erde untertan") befiehlt nicht die rücksichtslose Ausbeutung der Erde, aber es verbietet deren Anbetung und läuft im Grunde auf dasselbe Ziel hinaus wie das Bilderverbot. Auch hier geht es ja nicht nur um die Unabbildbarkeit Gottes, sondern um das Verbot, überhaupt Bilder beliebiger irdischer, himmlischer und unterirdischer Wesen herzustellen, weil im Akt der Bildschöpfung schon ein Moment der Anbetung gesehen wird. Damit setzt sich der biblische Schöpfungsglaube bewusst in diametralen Gegensatz zu den Schöpfungsvorstellungen seiner "heidnischen“ Umwelt. Diese beruhten, wiè wir das für Ägypten gezeigt haben, ganz im Gegenteil auf der Vorstellung von der Inganghaltungsbedürftigkeit der Welt. Die Welt ist hier gerade kein selbstregulierendes System, sondern einer ständigen Gravitation zum Chaos, zu Stillstand und Auflösung ausgesetzt. Der Schöpfer kann sie keineswegs sich selbst überlassen; er muss sie als Sonne unablässig umkreisen und alle 
großen und kleinen Götter müssen ihm bei diesem Werk der Inganghaltung beistehen. Jeden Tag und jede Nacht muss der Feind in der Himmelshöhe und in den Tiefen der Unterwelt besiegt werden. Der Fortbestand der Welt hängt nicht vom Willen Gottes ab, sondern von seiner Kraft, sie in Gang zu halten. Dass dies sein Wille ist, wird unterstellt. Für die Menschen ergibt sich daraus, dass sie, ganz im Gegensatz zum Menschen der Bibel, zu unablässiger anbetender Mitwirkung und Anteilnahme aufgefordert sind. Sie müssen Sonne und Mond mit Hymnen und Opfern begleiten, sie müssen die Nilüberschwemmung ermuntern und begütigen, Aussaat und Ernte mit Riten begleiten, die Tiere heilig halten und das ganze kosmische und natürliche Leben mit andächtiger Aufmerksamkeit beobachten und bewahren. Wenn die Ägypter aufhörten, den Kosmos anzubeten, würde in ihren Augen die Welt unbewohnbar werden. Davon handelt ein ägyptischer Text der Spätantike, der schon Auge in Auge mit dem heraufziehenden Christentum entstanden ist:

Und doch wird eine Zeit kommen, wenn es so aussieht, als hätten die Ägypter vergeblich die Gottheit verehrt mit frommem Herzen und unablässiger Hingabe und alle heilige Hinwendung zu den Göttern wird vergeblich und ihrer Früchte beraubt sein. Denn die Gottheit wird von der Erde wieder zum Himmel aufsteigen und Ägypten verlassen. Dieses Land, einst der Sitz der Religion, wird nun der göttlichen Gegenwart beraubt sein. Fremde werden dieses Land bevölkern, und die alten Kulte werden nicht nur vernachlässigt, sondern geradezu verboten werden. Von der ägyptischen Religion werden nur Fabeln übrig bleiben und beschriftete Steine. $<\ldots$. .> In jenen Tagen werden die Menschen des Lebens überdrüssig sein und aufhören, den Kosmos (mundus) zu bewundern und zu verehren. Dieses Ganze, so gut, dass es nie etwas Besseres gab, gibt noch geben wird, wird in Gefahr sein, unterzugehen, die Menschen werden es für eine Last ansehen und es verachten. Sie werden diese Welt, das unvergleichliche Werk Gottes, nicht länger lieben, diesen glorreichen Bau, gefügt aus einer unendlichen Vielfalt von Formen, Instrument (machina) des göttlichen Willens, der seine Gunst rückhaltlos in sein Werk verströmt, wo sich in harmonischer Vielfalt alles, was der Anbetung, Lobpreisung und Liebe wert ist, als Eines und Alles zeigt. Finsternis wird man dem Licht vorziehen und Tod dem Leben. Niemand wird seine Augen zum Himmel erheben. Den Frommen wird man für verrückt halten, den Gottlosen für weise und den Bösen für gut. $\langle\ldots\rangle$

Die Götter werden sich von den Menschen trennen - o schmerzliche Trennung! - und nur die bösen Dämonen werden zurückbleiben, die sich mit den Menschen vermischen und die Elenden mit Gewalt in alle Arten 
von Verbrechen treiben, in Krieg, Raub und Betrug und alles, was der Natur der Seele zuwider ist.

In jenen Zeiten wird die Erde nicht länger fest sein und das Meer nicht mehr schiffbar, der Himmel wird die Sterne nicht in ihren Umläufen halten noch werden die Sterne ihre Bahn im Himmel einhalten; jede göttliche Stimme wird notwendig zum Schweigen kommen. Die Früchte der Erde werden verfaulen, der Boden wird unfruchtbar werden und die Luft selbst wird stickig und schwer sein. Das ist das Greisenalter der Welt: das Fehlen von Religion (inreligio), Ordnung (inordinatio) und Verständigung (inrationabilitas)..$^{2}$

Was uns dieser Text vor Augen führt, ist die Vorstellung, dass die Welt "vergreist" und unbewohnbar wird, wenn die Menschen aufhören, sich an ihrer Inganghaltung durch Riten und Anbetung zu beteiligen. Wie wirkt sich dieser Gedanke, die Welt in Gang halten zu müssen, auf die Vorstellung von der menschlichen Kreativität aus? Einerseits könnte man das für den Ausdruck eines Allmachtswahns halten, der sich einbildet, mit Hymnen und Räucherwerk etwas dazu beitragen zu können, dass etwa die Sonne am Morgen aus dem Horizont herauskommt und den Aufstieg zur Himmelshöhe schafft. Andererseits spricht sich darin aber auch das Bewusstsein einer Eingebundenheit menschlichen Wollens und Strebens in die elementaren Vorgänge der natürlichen und kosmischen Umwelt aus, die auch die Möglichkeiten der menschlichen Kreativität gebunden hält. Solange die Menschen in einer Welt lebten, von der sie glaubten, sie in Gang halten zu müssen, waren die Bedingungen für die Entstehung der uns vertrauten Formen und Medien philosophischer und technologischer Weltaneignung und Weltbeherrschung nicht gegeben. Dazu bedurfte es der Emanzipation vom Zwang der Inganghaltung und der Gewinnung von Distanz und Perspektive, wie sie im Westen vor allem durch zwei ganz verschiedene, aber in ihrem Ergebnis konvergierende Durchbrüche geleistet wurde: den biblischen Monotheismus mit seiner scharfen Trennung von Gott und Welt, Schöpfer und Schöpfung, und die griechische Metaphysik mit ihrer ebenso scharfen Trennung zwischen der sinnlichen und der intelligiblen Welt, der Welt des Werdens und der Welt des Seins. Beide Schritte haben den Menschen befreit vom Geschäft der Weltinganghaltung, und vor beide Schritte müssen wir gedanklich zurückgehen, wenn wir das ägyptische Denken verstehen wollen.

52 Asclepius 24-26 ed. Nock-Festugière, Corpus Hermeticum, Collection Budé 1960, S. 326329; koptische Fassung: Nag Hammadi Codex VI, 8.65.15-78.43 ed. Krause-Labib 1971, S. 194-200. 


\section{Literatur}

Hönigswald R (1957) Vom erkenntnistheoretischen Gehalt alter Schöpfungserzählungen, Stuttgart

Assmann A (1980) Die Legitimität der Fiktion, München

Blumenberg H (1981) Die Lesbarkeit der Welt, Frankfurt a.M.

Lyotard, JF (1985) Immaterialität und Postmoderne, Berlin

Bickel S (1994) La cosmogonie égyptienne avant le Nouvel Empire, OBO 134, Freiburg/Göttingen

Sethe K (1929) Amun und die acht Urgötter von Hermupolis, APAW

Schlögl HA (1977) Der Sonnengott auf der Blüte. Eine ägyptische Kosmogonie des Neuen Reichs, AegHelv 5

Sethe K (1908) Die altägyptischen Pyramidentexte, Leipzig

Barta B (1973) Untersuchungen zum Götterkreis der Neunheit, MÄS 28

de Buck A (1935-1971) The Egyptian Coffin Texts, 7 Bde, Chicago

Hornung E (1982) Der ägyptische Mythos von der Himmelskuh: eine Ätiologie des Unvollkommenen, OBO 46

Beinlich H (1991) Das Buch vom Fayum. Zum religiösen Eigenverständnis einer ägyptischen Landschaft, Wiesbaden 1991

Assmann J (1975) Ägyptische Hymnen und Gebete, Zürich und München

Assmann J (1983) Re und Amun. Die Krise des polytheistischen Weltbilds im Ägypten der 18.20. Dynastie, Fribourg

Budge E A W (1898) The Book of the Dead, London

Brunner H (1983) „Seth und Apophis - Gegengötter im ägyptischen Pantheon?“, in: Saeculum $34,226-234$

Fecht F (1972) Der Vorwurf an Gott in den Mahnworten des Ipuwer, AHAW

Dieterich A (1891) Abraxas

Sauneron S (1962) Les fêtes religieuses d'Esna aux derniers siècles du paganisme, Kairo

Breasted J H (1902) „Philosophy of a Memphite Priest“, in: Zeitschr.f.äg.Sprache 39, 39-54

Erman A (1909) Ein Denkmal memphitischer Theologie, Sitzungsber. d. Preuss. Ak. d. Wiss Berlin

Sethe K (1928) Dramatische Texte zu altägyptischen Mysterienspielen UAÄG 10, Leipzig

Junker H (1939) Die Götterlehre von Memphis, Sitzungsber. d. Preuss. Ak. d. Wiss. Jg. 1939 Nr.23, Berlin

Junker H (1941) Die politische Lehre von Memphis, ibd., Jg. 1941 Nr 6, Berlin

Allen J P (1988) Genesis in Egypt. The Philosophy of Ancient Egyptian Creation Accounts, New Haven 1988

Junge F (1973) „Zur Fehldatierung des sog. Denkmals memphitischer Theologie, oder: Der Beitrag der ägyptischen Theologie zur Geistesgeschichte der Spätzeit“, in: Mitt. d. Dt. Archäol. Inst. Kairo 29, 1973, $195 \mathrm{ff}$.

Schlögl HA (1980) Der Gott Tatenen, nach Texten und Bildern des Neuen Reichs, OBO 29, Fribourg

Fowden, G (1986) The Egyptian Hermes. A historical approach to the late pagan mind, Cambridge

Gardiner A H (1947) Ancient Egyptian Onomastica, Text, vol 1, Oxford

\section{Abbildungsnachweis}

[1] Foto: Autor

[2] H. Bonnet, in: Bilderatlas zur Religionsgeschichte, 2.-4. Lieferung: Ägyptische Religion, Leipzig 1924, Abb. 8

[3] A. Piankoff, The Shrines of Tut-Ankh-Amon, S. 142, Fig. 36 